\title{
1 Structural and functional properties of soy protein isolate and cod gelatin blend films
}

2

3 Gabriela A. Denavi ${ }^{\mathrm{a}}$, Miriam Pérez-Mateos ${ }^{\mathrm{b}}$, María C. Añón ${ }^{\mathrm{a}}$, Pilar Montero ${ }^{\mathrm{b}}$, Adriana N.

4 Mauri $^{\mathrm{a},}$,, M. Carmen Gómez-Guillén ${ }^{\mathrm{b}}$.

5

$6 \quad{ }^{a}$ Centro de Investigación y Desarrollo en Criotecnología de Alimentos (CIDCA). 47 y 116

7 (1900) La Plata, Argentina

8

9 ' Instituto del Frío (CSIC), José Antonio Novais, 10 - E28040 Madrid, Spain

10

11

12

* Corresponding author: Tel. / Fax: +54 2214890741.

E-mail address: anmauri@quimica.unlp.edu.ar (A.N. Mauri). 


\section{Abstract}

14 The structure-function relationship of composite films obtained from soy protein isolate (SPI) 15 and cod gelatin was studied. Films with different ratios of SPI:gelatin (0, 25, 50, 75, 100\% w/w) 16 plasticized by a mixture of glycerol and sorbitol, were prepared by casting. Regardless of the 17 soy protein concentration, the thickness and water vapor permeability of the composite films 18 diminished significantly as compared to pure gelatin films. The formulation containing $25 \%$ 19 SPI: 75\% cod skin gelatin had the maximum force at the breaking point which was 1.8-fold and 202.8 -fold of those of $100 \%$ gelatin and $100 \%$ SPI films, respectively. Moreover, this formulation 21 offered high percent deformation values as the $100 \%$ gelatin film and relatively low water vapor permeability as the $100 \%$ SPI film. While all the films exhibited high water solubility, a slight reduction of the protein released in water was observed with increasing soy contents. DSC analyses revealed that gelatin was completely denatured in all the films, while the soy proteins maintained most of their native conformation. The FTIR analysis revealed the presence of $25 \%$ SPI to produce gelatin conformational changes, self aggregation of gelatin $\alpha$-chains as well as intermolecular associations through $\mathrm{C}=\mathrm{O}$ bonds between gelatin and SPI proteins.. Regarding appearance, all the films were translucent, but the yellowish color ( $\left.\mathrm{b}^{*}\right)$ increased with increasing proportions of soy proteins.

Keywords: edible films, soy proteins, cod gelatine, structural properties, mechanical properties, water vapour permeability, FTIR. 
37 The production of biodegradable materials from renewable biopolymers, such as proteins, appears as an interesting alternative, at least for some applications, to synthetic polymers whose accumulation contributes greatly to environmental pollution. The functionality of protein films are determined by their microstructure, which varies significantly depending on the initial protein structure and the preparation method (Denavi, Tapia, Añón, Sobral, Mauri \& Menegalli, 2008). All the aspects of protein structure (primary, secondary, tertiary and quaternary) determine primarily the ability of protein chains to interact between them and also with other components of the formulation considered. The type and concentration of the interactions involved in the stabilization of the proteinaceous matrix (covalent -disulfide bonds- and noncovalent -hydrogen bonds, electrostatic, hydrophobic) is determined by the amino acid composition and the molecular weight of the protein (which vary significantly for different proteins) and by the experimental parameters used in film preparation. The protein-protein interactions involved in film formation determine the degree of cross-linking and the hydrophylic-hydrophobic character of the films, and correlate with their physicochemical, mechanical and barrier properties (Mauri \& Añón, 2006 and 2008). The aim of preparing films from mixtures of structurally different proteins is to obtain composite materials in which each component provides a determined functional property. (Damodaran \& Paraf, 1997; Sabato, et al., 2001; Barreto, Pires \& Soldi, 2003; Longares, Monahan, O’Riordan \& O’Sullivan, 2005, Chambi \& Grosso, 2006; Güçbilmez, Yemenicioğlu \& Arslanoğlu, 2007; Cao, Fu \& He, 2007). In particular, soy proteins and gelatin are very different regarding their origin, structure and amino acid composition. Soy proteins, of vegetal origin, are formed by a mixture of albumins and globulins, $90 \%$ of which are storage proteins with globular structure, mainly formed by 7S globulins, or $\beta$-conglycinin, and 11S globulin, or glycinin. Globulin 7S is a trimer of molecular mass 150-200 kDa formed by four subunits, from which $\alpha$ (72 kDa), $\alpha^{\prime}$ (68 kDa) and $\beta$ (52 kDa) are the most important while the $\gamma$ subunit (with a molecular mass similar to $\beta$ ) is a minor component. All these subunits have similar amino acid Food Hydrocoll. 2009; 23(8) 2094-2101 

sequences, and are poor in cysteine, methionine and tryptophan. On the other hand, the 11S globulin or glycinin is an hexamer of molecular mass $300-380 \mathrm{kDa}$, in which each subunit is composed of an acidic polypeptide (acid pI, $\sim 35 \mathrm{kDa}$ ) and a basic polypeptide (basic pI, $\sim 20$ $\mathrm{kDa}$ ) linked by a disulfide bond, with a cystein, methionine and tryptophan content higher than that of 7S globulin (Nielsen, 1985a and b; Thanh \& Shibasaki, 1977; Staswick, Hermedson, \& Nielsen, 1984). On the other hand, gelatin is a mixture of polypeptides derived from hydrolysis of collagen contained in bones and skins. The collagen rod, composed of three f-chains of around $100 \mathrm{kDa}$ each, can be solubilized in acid without altering its original triple-helix configuration. Subsequent thermal treatment cleaves hydrogen and covalent bonds; leading to destabilization of the triple helix by means of a helix-to-coil transition (Djabourov et al., 1993) and conversion into soluble gelatin, which has a definite molecular weight distribution pattern corresponding to the $\alpha$-chains and its oligomers (Ledward, 1986). As shown in previous studies, cod skin gelatin contains $\alpha$-chains, $\beta$ - and $\gamma$-components (covalently linked $\alpha$-chain dimmers and trimmers, respectively), and also an appreciable amount of higher molecular weight polymers as well as fractions of molecular weight lower than that of $\alpha$-chains (Gómez-Guillén, Turnay, Fernández-Díaz, Ulmo, Lizarbe \& Montero, 2002). According to the same study cod skin gelatin is mostly composed of Gly (34\%), iminoacids (Pro+Hyp, 16\%) and Ala residues (10\%). As for most gelatins derived from type I collagen, cysteine and tryptophan were absent, and the content of Tyr residues was below $1 \%$.

The structural differences between soy and gelatin proteins are reflected in their functionality, consequently, in the characteristics of the films they form, although both proteins may exhibit good film-forming properties. SPI films have been reported to be rather brittle and coloured, and to have relatively poor mechanical properties (Ghorpade, Li, Gennadios \& Hanna, 1995; Rhim, Gennadios, Handa, Weller \& Hanna, 2000; Kim, Weller, Hanna \& Gennadios, 2002; Mauri, et al., 2008). On the other hand, fish gelatin form transparent, weakly colored, and highly extensible films (Jongjareonrak, Benjakul, Visessanguan \& Tanaka, 2006; Avena-

89 Bustillos et al., 2006; Gómez-Guillén, Ihl, Bifani, Silva \& Montero, 2007; Zhang, Wang, 90 Herring \& Oh, 2007; Carvalho et al., 2008). However, the main drawback of cod gelatin films is 
91 their low water resistance and their extremely high solubility (Piotrowska, Kolodziejska,

92 Januszewska-Jozwiak \& Wojtasz-Pajak, 2005; Pérez-Mateos, Montero \& Gómez-Guillén, 93 2009).

94 Taking into account the best characteristics of soy and gelatin proteins it can be speculated that

95 their combination would lead to improved films as compared to those formed by each material

96 individually. In a recent article, Cao et al. (2007) described the diverse functional properties of

97 composite films made from soy protein isolate and type B- bovine-bone gelatin, suggesting that

98 complex films have an increased range of applications due to the different mechanical and

99 barrier properties of their components.

100 The goal of the present work was to study the formation and the characteristics of composite

101 films obtained from cod skin gelatin and soy protein isolates mixed in different proportions, and

102 to analyze the structure-function relationship of such mixtures.

103

104 2. Materials and methods

105

106 2.1. Soy protein Isolate (SPI) preparation.

107 Soy protein isolate was prepared from defatted low-heat soybean meal produced by Bunge-

108 Ceval SA (Brazil) as described by Petruccelli \& Añón (1995). Protein content of SPI was

$10983.82 \% \pm 0.14 \%$ protein on a dry basis, determined by the Kjeldahl technique (Nx5.7).

110

$111 \quad$ 2.2. Fish skin gelatin.

112 Cod (Godus morhua) skin gelatin was obtained using a mild acid pre-treatment followed by

113 overnight extraction by water at $45^{\circ} \mathrm{C}$, as reported in Gómez-Guillén \& Montero (2001). The

114 protein content of the dry gelatin powder was $84.4 \% \pm 0.23(\mathrm{~N}$ x 5.4) as determined with a

115 Nitrogen analyzer LECO FP-2000 (Leco Corporation, St Joseph, MI) calibrated with EDTA

116 (Dumas method following A.O.A.C. 992.15) (A.O.A.C. 2000).

118 2.3. Preparation of films

Food Hydrocoll. 2009; 23(8) 2094-2101 
119 Five groups of composite films with different ratios of soy protein isolate to gelatin (0:100, 25:75,

120 50:50, 75:25 and 100:0) were prepared. Aqueous solutions of $4 \%$ soy protein isolate and/or

121 gelatin (w/v) were prepared in $250 \mathrm{~mL}$ Erlenmeyer flasks with $1.5 \%$ plasticizers $(0.75 \%$ glycerol

$122+0.75 \%$ sorbitol). Dry proteins were dissolved in distilled water with stirring, at room

123 temperature in the case of soy protein and heating at $60^{\circ} \mathrm{C}$ in a water bath in the case of gelatin.

124 Once they were completely dissolved, $\mathrm{pH}$ was adjusted to 10.5 using $2 \mathrm{~N} \mathrm{NaOH}$ for both proteins,

125 based on previous findings about the effect of $\mathrm{pH}$ on the properties of soy protein films (Mauri et

126 al, 2006 and 2008). Then protein solutions were mixed at the different ratios shown in Table 1. 40

$127 \mathrm{~mL}$ of the film-forming solution were poured on plexiglass plates $(11.5 \times 11.5 \mathrm{~cm})$ and were

128 dehydrated at $45^{\circ} \mathrm{C}$ in an oven with air flow and circulation (Binder FD 240, Tuttlingen,

129 Germany) for $18-20 \mathrm{~h}$. Dry films were conditioned at room temperature and 58\% relative

130 humidity in desiccators with saturated solutions of $\mathrm{NaBr}$ for two days, and were subsequently

131 peeled from the casting surface for characterization analyses. The nomenclature of films is shown

132 in Table 1.

133

134 2.4. Thickness

135 Film thickness was measured with a digital micrometer (Mitutoyo MDC-25M, Kanagawa, 136 Japan). For each film, values obtained at nine different positions were averaged.

138 2.5. Water solubility and protein soluble matter

139 Films solubility was determined in triplicate, according to the method proposed by Gontard,

140 Guilbert \& Cuq (1992). Three pieces of film (2 cm in diameter, about $0.25 \mathrm{~g}$ total) were

141 immersed in $50 \mathrm{~mL}$ distilled water and the system was gently shaken at room temperature (22-

$14225^{\circ} \mathrm{C}$ ) for 24 hours. Then, the samples were filtered through a filter paper (Whatman 1). The

143 unsolubilized fraction was dried in a forced air oven $\left(105^{\circ} \mathrm{C}, 24\right.$ hours $)$ in order to determine

144 the water soluble matter as a percentage of the initial weight.

145 The protein content of the soluble fraction was measured with a Nitrogen analyzer LECO FP-

1462000 (Leco Corporation, St Joseph, MI) calibrated with EDTA (Dumas method following Food Hydrocoll. 2009; 23(8) 2094-2101 
147 A.O.A.C. 992.15) (A.O.A.C. 2000). Results are the average of three determinations and are

148 expressed as percent protein solubilized with respect to $100 \mathrm{~g}$ of film (Nx5.7 for SPI; Nx5.4 for

149 cod gelatin; N x 5.5 estimated for the mixture of SPI and cod gelatin).

150

151

\subsection{Electrophoretic analysis (SDS-PAGE)}

152 Aliquots of the water soluble fractions of the films $(15 \mu \mathrm{L})$ were mixed with $200 \mu \mathrm{L}$ of loading

153 buffer (12.5\% SDS, 25\% mercaptoethanol, $50 \mathrm{mM}$ Tris-HCl, $5 \mathrm{mM}$ ethylenediaminetetraacetic

154 acid (EDTA), 10 \% glycerol and 0.002\% bromophenol blue) until reaching a final concentration

155 of $2 \mathrm{mg} / \mathrm{mL}$ of protein. Samples were heat-denatured $5 \mathrm{~min}$ at $90{ }^{\circ} \mathrm{C}$ and analyzed by SDS-

156 PAGE according to Laemmli (1970) using 7.5\% gels in a Mini Protean II unit (Bio-Rad

157 Laboratories, Hercules, CA) at $30 \mathrm{~mA} /$ gel. The loading volume was $20 \mu \mathrm{L}$ in all lanes. Protein

158 bands were stained with Coomassie Brilliant Blue (R-250, Merck). An aqueous solution of 30\%

$159(\mathrm{v} / \mathrm{v})$ methanol and $10 \% \mathrm{v} / \mathrm{v}$ acetic acid was used for destaining, and an aqueous solution of 5\%

$160(\mathrm{w} / \mathrm{v})$ glycerol and 10\% (v/v) acetic acid was used as storage solution. Two mixtures of known

161 proteins covering different molecular weight ranges (Amersham Biosciences, Buckinghamshire,

162 England)-were used for reference. The high molecular weight standard contained myosin (220

$163 \mathrm{kDa}$ ), $\alpha_{2}$-macroglobulin (170 kDa), $\beta$-galactosidase (116 kDa), transferrin (76 kDa), and

164 glutamic acid dehydrogenase $(53 \mathrm{kDa})$. The low molecular weight standard contained 165 phosphorilase b (97 kDa), albumin (66 kDa), ovalbumin (45 kDa), carbonic anhydrase (30

$166 \mathrm{kDa})$, trypsin inhibitor (20.1 kDa) and $\alpha$-lactalbumin $(14.4 \mathrm{kDa})$.

167

$168 \quad$ 2.7. Light absorption

169 The light barrier properties of films were determined by measuring their light absorption at 170 wavelengths ranging from $690 \mathrm{~nm}$ to $280 \mathrm{~nm}$, using a UV-1601 spectrophotometer (Model 171 CPS-240, Shimadzu, Kyoto, Japan). The transparency of the films was calculated by the 172 equation $\mathrm{T}=\mathrm{Abs}_{600} / x$, where $\mathrm{Abs}_{600}$ is the absorbance at $600 \mathrm{~nm}$ and $x$ is the film thickness $173(\mathrm{~mm})$.

\section{2.8. Fourier transform infrared spectroscopy (FTIR).}

Food Hydrocoll. 2009; 23(8) 2094-2101 
175 Pieces of film $2 \mathrm{~cm}$ in diameter were sandwiched between two $\mathrm{KBr}$ disks. FTIR spectra were

176 recorded from wavenumber 400 to $4000 \mathrm{~cm}-1$ in a Bruker IFS28 spectrometer (Bruker Banner

177 Lane, Coventry, UK). Absorbance spectra were obtained with a spectrum of the KBr disk as

178 background. In all, 50 interferograms were compiled for each spectrum.

\subsection{Differential Scanning Calorimeter}

181 A Polymer Laboratories Rheometrics Scientific DSC (Church Stretton, UK) was used for these

182 studies. Temperature and heat flow calibration of the equipment was carried out according to

183 ASTM Standards. Lauric acid and indium were used as temperature standards; the latter was

184 also used as a heat-flow standard. SPI, cod gelatin and films were studied by DSC, in order to 185 determine the conformational state of both proteins. Hermetically sealed aluminum pans 186 containing $10-15 \mathrm{mg}$ of samples were prepared. The capsules were scanned at $10^{\circ} \mathrm{C} / \mathrm{min}$ over 187 the range $30-150^{\circ} \mathrm{C}$. An empty double capsule was used as a reference.

\subsection{Water vapour permeability measurements}

190 Water vapor permeability was determined following the method described by Sobral et al. (2001). 191 Samples were cut from each film and mounted on plastic cups (permeation area $=15.90 \mathrm{~cm}^{2}$ ) containing silica gel, and then the cups were placed in desiccators with distilled water. Weights were measured every hour for 6 hours. Water vapor permeability was calculated from the equation $\mathrm{WVP}=w x t^{-1} A^{-1} \Delta P^{-1}$, where $w$ is the weight gain (g), $x$ is the film thickness (mm), $t$ is the time of gain (h) and $\Delta P$ is the difference of partial vapor pressure of the atmosphere with silica gel and pure water (2642 $\mathrm{Pa}$ at $22^{\circ} \mathrm{C}$ ). Results were expressed as $\mathrm{g} \mathrm{mm} \mathrm{h}^{-1} \mathrm{~cm}^{-2} \mathrm{~Pa}^{-1}$. All tests were made in triplicate.

\subsection{Mechanical properties}

200 Films were fixed in a $5.6 \mathrm{~cm}$ diameter cell and perforated to breaking-point using a texturometer

201 (Instron 4501, Instron Engineering Corp., Canton, MA, U.S.A.) with a round-ended stainless steel 202 plunger $(\varnothing=3 \mathrm{~mm})$. Cross-head speed was $60 \mathrm{~mm} / \mathrm{min}$ and a $100 \mathrm{~N}$ load-cell was used. Breaking Food Hydrocoll. 2009; 23(8) 2094-2101 
203 force was expressed in $\mathrm{N}$ and breaking deformation in \%, according to Sobral, Menegalli,

204 Hubinger \& Roques (2001). All determinations are the means of at least five measurements.

205

206

\subsection{Color}

207

Films were placed between two steel dishes with a hole of $5.7 \mathrm{~cm}$ diameter. The color of films was determined with a tristimulus colorimeter (HunterLab D25 A-9, Hunter Associates Laboratory Inc., Reston, VA., USA) using the CIE Lab scale $\left(\mathrm{C} / 2^{\circ}\right)$ where $\mathrm{L}^{*}, \mathrm{a}^{*}$ and $\mathrm{b}^{*}$ are the parameters that measure lightness, redness and yellowness, respectively. A standard white plate

211 with reflectance values of $L^{*}=93.68, a^{*}=-0.69, b^{*}=-0.88$, was used as reference. The result was

212 the average of five measurements taken at ambient temperature at different points on the sample.

\subsection{Statistical analysis.}

Data were subjected to one-way analysis of variant (ANOVA) using SPSS computer program

216 (SPSS 14, SPSS INC., Chicago, Illinois, USA), means were compared using Bonferroni test with

217 level of significance set at $\mathrm{p}<0.05$. Pearson or Spearman's rho correlations ( $\mathrm{p}<0.01$ or 0.05 ) were

218 calculated to analyze dependence of film characteristics on the ratio of soy protein isolate :gelatin.

219

\section{Results and Discussion}

221

222

The thickness, water content, water solubility and soluble protein content of the films obtained

223 are shown in Table 2. It can be observed that all the films containing soy protein isolate

224 (regardless of its proportion) had a similar thickness, which in all cases was significantly thinner

225 than those of films made from gelatin alone. It can be also observed that film containing only soy proteins exhibited water content significantly higher than that of the film containing only gelatin, while composite films had intermediate water contents without significant differences among them. It is interesting to note that in spite of the use of the same total protein mass and drying conditions for preparing all films, those containing gelatin had a higher thickness in spite

230 of their lower water content. This indicates a higher compaction degree of the film matrix when Food Hydrocoll. 2009; 23(8) 2094-2101 
231 soy proteins are present, suggesting a different degree of molecule unfolding or cross-linking

232 within the protein network of the film.

233

234 Solubility properties

235 All the films exhibited a water solubility above 80\% (Table 2), gelatin films being slightly

$236(\mathrm{p} \leq 0.05)$ more soluble than SPI films. This would indicate a poor water resistance, although for

237 some applications could be interesting, for example, as a carrier of bioactive compounds. The

238 solubility tended to decrease with increasing the SPI proportion in the composite films, although

239 differences were found not significant $(\mathrm{p}>0.05)$. It is worth noting that the water insoluble film

240 fraction in the composite films did not preserve the initial integrity but appeared as a viscous

241 mass, mostly due to the presence of swelled aggregated gelatin, and this might account for a

242 considerable high variability in the results. In the case of films made from pure gelatin, the

243 results obtained agree with those reported by Carvalho, et al. (2008) for films elaborated from

244 two differently processed Atlantic halibut skin gelatins, as well as by Piotrowska, et al. (2005)

245 and Pérez-Mateos, et al. (2009) for cod skin gelatin films, but were considerably higher than

246 those reported for bovine gelatin films (around 30 \%) (Bertan et al., 2005; Gómez-Estaca,

247 Montero, Fernández-Martín, Gómez-Guillén, 2008). It is known that, compared to mammalian

248 gelatins (Norland, 1990; Montero et al., 1990), cold water fish gelatins are characterized by a

249 lower content in intra- and interchain covalent crosslinks mainly involving lysine and

250 hydroxylysine residues as well as aldehyde derivatives, which may be responsible for such a

251 higher film solubility. On the other hand, solubility values for pure soy films were higher than

252 those reported by other authors (Stuchell \& Krochta, 1994; Kunte, Gennadios, Cuppett, Hanna

253 \& Weller, 1997; Cho \& Rhee, 2004,). Denavi et al. (2008) have shown that the solubility of

254 films prepared by casting from native soy protein isolates using glycerol as plasticizer was

255 significantly affected by drying conditions. They also reported solubilities higher than 80\%

256 when films were dried at low temperatures and low relative humidities (conditions also used in

257 the present work), and attributed this finding to the fact that proteins are not denatured under

258 these conditions thus not favoring the interactions between chains (including thiol/disulphide -

Food Hydrocoll. 2009; 23(8) 2094-2101 
SH/SS- interchange reactions) and facilitating the subsequent solubility of the films. The same

260 explanation may apply to the findings of the present study.

261 While no significant differences in solubility change of films were observed, it was verified that the amount of protein released from the films upon water solubilization (Table 2) was significantly higher $(\mathrm{p} \leq 0.05)$ in the pure gelatin film, as well as in the composite films where SPI did not exceed 50\%. The high compaction of all the films containing soy proteins would be expected to hamper the protein-solvent contact thus reducing the solubility of these films as compared to $100 \%$ gelatin ones. However, this fact did not explain the behavior of composite films, all of which had a similar thickness that was notably lower than that of $100 \%$ gelatin films. Thus, in accordance to Voutsinas, Cheung and Nakai (1983), the lower protein solubility in the films with the highest SPI ratio (i.e. 100S:0G and 75S:25G) was mainly attributed to the higher surface hydrophobicity of soy proteins as compared to gelatin ones.

\section{Electrophoretic analysis}

273 The SDS-PAGE analysis of the protein fraction released upon film water solubilization is shown in Figure 2. A clear difference between 100\% SPI and 100\% G films was observed, so much in the type of bands as in their intensity. As expected, gelatin soluble fractions exhibited molecular weights notably higher than those of soy proteins ones. Moreover, the bands corresponding to the gelatin polipeptides appeared with a considerably higher intensity than the soy protein bands, which was in agreement to the higher amount of soluble protein in the gelatin films than in the SPI films. The protein released from gelatin films showed bands that could be identified mainly as $\alpha_{1^{-}}$and $\alpha_{2}$-chains ( $\left.\sim 100 \mathrm{KDa}\right)$, b-components $(\sim 200 \mathrm{KDa})$ and higher molecular weight aggregates, with a distribution similar to that of the gelatin originally used for film preparation (Gómez-Guillén et al., 2002). This finding indicates that all fractions, including those of very high molecular weight, are soluble in water, which is in accordance with the high

284 film water solubility. Proteins released from SPI films upon water solubilization included lower 285 molecular weight components $(<80 \mathrm{KDa})$ that may be attributed to the polypeptides that 286 constitute the two mains globulins present in SPI, i.e. acidic polypeptide chains (A: 37-40 KDa) Food Hydrocoll. 2009; 23(8) 2094-2101 
and basic polypeptide chains (B: 9.9-20 KDa), and the $\mathrm{AB}$ subunit $(\sim 60 \mathrm{KDa})$ of glycinin

288 globulin (11S), and subunits $\alpha^{\prime}(83-57 \mathrm{KDa}), \alpha(76-57 \mathrm{KDa})$ and $\mathrm{b}(53-42 \mathrm{KDa})$ of b-

289 conglycinin (7S). Notably, soluble aggregates of higher molecular weight, previously found in

290 other studies (Mauri et al, 2006), were not observed among soy polypeptides in the present

291 work. Regarding the composite films, the SPI bands exhibited a similar intensity in all

292 formulations irrespective of the SPI proportion in the film. On the contrary, gelatin molecules

293 showed a noticeable decrease in the intensity of the different bands when $25 \%$ gelatin was

294 replaced by 25\% SPI in the formulation of the composite films (25S:75G). This strongly

295 suggested some gelatin aggregation in the presence of a low amount of soy proteins, which

296 would hinder its solubilization in water. This event, however, could not be clearly evidenced by

297 determining the film water solubility or the soluble protein, since no significant differences

298 were found. As the SPI ratio increased, gelatin fractions were hardly visible, in part due to

299 molecule aggregation, but also to a dilution effect, as a result of the reduced gelatin ratio. This

300 was especially apparent in the 75S:25G formulation, in agreement with the significantly lower

301 values of soluble protein found.

302

303

Water vapour permeability

304 The WVP of the films is shown in Figure 3. It can be observed that the value of this measurement is significantly lower for soy films than for gelatin ones, and that the presence of soy proteins in composite films determines a reduction of WVP regardless of the amount of soy added, which is clearly related to the lower thickness of films containing soy proteins as well as to the more surface hydrophobic nature of the latter ones. As reported previously for other hydrophilic films (pectin, amylose, cellulose ethers, sodium caseinate and soy proteins), WVP increases with film thickness (McHugh, Avena-Bustillos \& Krochta, 1993; Ghorpade, et al.,

311 1995). In the present work, the replacement of 25\% cod gelatin by SPI (25S:75G) was enough

312 to induce a film matrix compaction which remained unaltered by increasing the soy protein

313 level. 
316 The puncture force and deformation of the studied films as measured in compression assays are 317 shown in Figures 4a and 4b, respectively. Gelatin films exhibited greater deformation (at least 318 10-fold higher since gelatin films did not break under the conditions assayed) and greater 319 breaking force (1.8-fold higher) than that of soy ones. Regarding composite films, it can be 320 observed that deformation increases progressively with gelatin proportion in the mixture, and 321 that 50S.50G and 25S:75G samples exhibit breaking forces higher than those of films made 322 from gelatin alone. Cao et al. (2007) reported that the mechanical properties in the tensile test of 323 composite films made from type B- bovine-bone gelatin and soy isolate improved progressively with increasing gelatin proportions, but traction resistance, elongation and Young module of films prepared from gelatin alone were higher than those of all the composite films. The higher breaking force observed in the current study for 50S:50G and 25S:75G films suggests a reinforcement of the film matrix probably induced by a certain degree of protein cross-linking involving both gelatin and SPI proteins.

Differential scanning calorimetry

The thermograms of films as determined by DSC are shown in Figure 1. It can be observed that cod gelatin is completely denatured in all films, while soy proteins are only partially denatured and conserve part of their native structure. The two endotherms in the thermograms of films containing soy proteins correspond to the thermal denaturation of 7S and 11S globulins. These denaturation temperatures are shift to higher values than those usually informed for these proteins (to 78 and $92{ }^{\circ} \mathrm{C}$ ), which is due to the low water content of the film (Hägerdal \& Martens, 1976; Mauri et al., 2006). The denaturation heat values associated to these endotherms were lower than those of native proteins and similar to those reported previously (Mauri et al., 2006) for similar soy protein isolate film-forming solutions at $\mathrm{pH} 10.5$, showing that the drying step at $45^{\circ} \mathrm{C}$ does not contribute to soy globulins denaturation. Although not pronounced, there

341 is a tendency to a slight upward shift of denaturation temperatures with increasing gelatin 342 proportions ( 3 and $7^{\circ} \mathrm{C}$ for the $25 \mathrm{~S}: 75 \mathrm{G}$ sample as compared to the $100 \mathrm{~S}: 0 \mathrm{G}$ sample), partially 
343 due to the lower water content of these films. This is accompanied by a small increase of 344 denaturation heat (the difference being $2.9 \mathrm{~J}$ per gram of soy protein in the samples mentioned 345 above). When the contribution of each fraction to the denaturation heat is analyzed separately, 346 the 11S fraction seems to be the one presenting a lower denaturation degree with increasing 347 gelatin proportions in the film (its denaturation heat increases), while the presence of gelatin 348 does not modify the state of the 7S fraction, whose denaturation heat stays approximately constant in all the formulations (including that formed from the soy protein isolate alone).

Fourier transform infrared spectroscopy (FTIR)

The FTIR spectra of cod skin gelatin films (0S:100G), soy protein isolate films (100S:0G), and their corresponding mixtures (25S:75G and 50S:50G) are shown in Figure 5. The gelatin film exhibited a sharp absorption band between 3550 and $3510 \mathrm{~cm}^{-1}$, which corresponds mainly to stretching vibrations of $\mathrm{OH}$ groups from adsorbed water molecules due to the relatively high hygroscopic nature of the film (Yakimets, Wellner, Smith, Wilson, Farhat, \& Mitchell, 2005). A similar band was also evident in the gelatin-SPI composite films, largely linked to the presence of gelatin. On the contrary, the SPI film showed a broad absorption range between 3500 and $3200 \mathrm{~cm}^{-1}$, which as reported by Guan, Qiu, Liu, Hua, \& Ma (2006) and Nanda, Rao, Kar, \&

361 Nayak (2007), will correspond mainly to free $-\mathrm{OH}$ and amines N-H stretching of the soy protein 362 isolate in the film.

363 The infrared spectra of blends films revealed noticeable changes to occur in the $1700-1650 \mathrm{~cm}^{-1}$ 364 region, as compared to the pure gelatin and SPI films. Regarding gelatin containing films, changes in this frequency range are indicative of changes in collagen or gelatin secondary structure involving the amide I region (Muyonga, Cole, \& Duodu, 2004). The spectrum of the cod gelatin film has been described in a previous work, where the gelatin was mixed with

368 increasing proportions of sunflower oil, revealing noticeable lipid-protein interactions (Pérez-

369 Mateos, et al., 2009). As reported previously, the main peaks observed at 1687 and $1656 \mathrm{~cm}^{-1}$ in 
370 the cod gelatin film were related to the predominance of helices of aggregated collagen-like 371 peptides and, to a lesser extent, of random coils.

372 On the other hand, the pure SPI film showed main relevant peaks at 1656, 1676 and $1687 \mathrm{~cm}^{-1}$. 373 A previous study (Kurose, Urman, Otaigbe, Lochhead, \& Thames, 2007) revealed well defined 374 peaks at 1658 and $1625 \mathrm{~cm}^{-1}$ in a film made with commercially available SPI, representing the 375 overlap of signals from $\alpha$-helix and random segments, and the contribution of $\beta$-sheets in the 376 secondary structure, respectively. These peaks were reported to increase with increasing 377 glycerol concentrations, by inducing activation of molecular chain motion. On the contrary, no 378 absorption band at around $1650-1658 \mathrm{~cm}^{-1}$ could be detected in another dried commercial SPI 379 (Nanda, et al., 2007), with no reported addition of glycerol or sorbitol. It is clear that intrinsic properties of the biopolymer and conditions used for film preparation (for example the use of certain plasticizers) are essential in determining the prevalence of secondary structure within the

382 film. The SPI film in the present work contained 37.5\% (g/100 g protein) of plasticizers 383 (glycerol plus sorbitol), which according to Kurose, et al. (2007) may have promoted the appearance of the peak at $1656 \mathrm{~cm}^{-1}$ associated to $\alpha$-helix structures. Similarly, the peaks at 1676 and $1687 \mathrm{~cm}^{-1}$ in the SPI film, which were also present to a lesser extent in the gelatin film spectra, may be related to interactions with the plasticizer through $\mathrm{C}=\mathrm{O}$ bonds. The extremely high pH (10.5) used for dissolving the SPI for film formation, very far from the isoelectric point $(\approx 4.5)$, may have induced a certain degree of soy protein unfolding favoring the interaction between the protein and the plasticizers, as was verified in DSC studies.

390 The gelatin-SPI mixtures, especially in the 25S:75G film, induced an increase of previously 391 existing peaks in gelatin or SPI films, as well as the appearance of new ones, which could be indicative of protein-protein interactions between both polymers. The higher intensity of the peaks at 1687 and $1656 \mathrm{~cm}^{-1}$, especially as compared to the pure gelatin film, denoted increased aggregation of gelatin polypeptide $\alpha$-chains with a concomitant increase in the amount of

395 disordered random coils, the latter largely coming from SPI fractions. The peak at $1676 \mathrm{~cm}^{-1}$ 396 was clearly visible in the 25S:75G film and, to a lesser extent, also in the 50S:50G film. Such an 397 FTIR event was scarcely appreciable in the pure gelatin film where it was present in the form of Food Hydrocoll. 2009; 23(8) 2094-2101 
a slight trace shoulder. Muyonga, et al. (2004) reported a peak at $1675 \mathrm{~cm}^{-1}$ that they ascribed to

399 the presence of $\beta$-turns in fish gelatin films. In agreement with these authors, and considering 400 the low SPI proportion in the 25S:75G film, the increase in the intensity of this peak in the 401 present study may reveal gelatin conformational changes induced by the presence of the SPI.

402 The appearance of peaks at $1702 \mathrm{~cm}^{-1}$ in the 25S:75G film, and to a lesser degree at $1697 \mathrm{~cm}^{-1}$ 403 in the 50S:50G film, denoted an increment in inter-molecular associations through $\mathrm{C}=\mathrm{O}$ bonds, 404 likely due to gelatin cross-linking favored by esterification reactions with SPI lateral reactive 405 groups. Similar peaks have been previously reported to occur in spectra from pigskin gelatin 406 with added lauric acid (Djagny, Wang, \& Xu, 2001) or in similar cod skin gelatin films added 407 with different concentrations of sunflower oil (Pérez-Mateos et al., 2009). The higher intensity 408 and frequency of appearance of the peak at $1702 \mathrm{~cm}^{-1}$ in the $25 \mathrm{~S}: 75 \mathrm{G}$ films, as compared to the 409 50S:50G film, clearly suggested that the gelatin-SPI interaction was stronger in the former.

410 From all the above findings, the replacement of $25 \%$ gelatin by SPI in the formulation of 411 composite films led to gelatin conformational changes producing a double effect: it favoured the 412 self-aggregation of gelatin polypeptide $\alpha$-chains, as well as a certain degree of interaction 413 between gelatin and SPI proteins. This may explain why the resulting film matrix was more 414 compact, as revealed by the reduced thickness, and gave rise to stronger and less deformable 415 films. Cao et al. (2007) reported that interactions between the amidogen and carboxyl of SPI 416 and gelatin might determine the improved mechanical properties of composite films, proposing 417 the hydrogen bonding as a main mechanism responsible for those interactions. To this respect, 418 our FTIR study revealed a more strong interaction via $\mathrm{C}=\mathrm{O}$ bonds. The higher degree of 419 compactness together with the more hydrophobic nature of the SPI proteins also caused the 420 WVP to decrease in the composite films. When the ratio of the SPI in the film was increased, 421 both gelatin cross-linking and gelatin-SPI interactions occurred to a lower extent, probably as a 422 result of the higher amount of SPI present in the matrix forming a network apart form gelatin, as 423 observed previously by DSC. This strongly suggests that, beyond a certain level, the SPI excess 424 may act as simple filler in the gelatin network, making films to be less resistant, and especially 425 less deformable, as being this the most striking feature of SPI films. Bearing also in mind the Food Hydrocoll. 2009; 23(8) 2094-2101 
426 relatively low molecular weight of SPI proteins and their globular nature, in contrast to the

427 gelatin polypeptides, this may explain why increasing the soy protein level did not significantly

428 affect the thickness of the composite films or the WVP.

429

430 Light barrier properties

431 Regarding the light barrier properties of films, Figure 6 shows the spectroscopic scanning of the

432 films at wavelengths between 690 and $280 \mathrm{~nm}$. All the spectra exhibited maxima at $290 \mathrm{~nm}$ and

$433295 \mathrm{~nm}$, which were much more noticeable with increasing soy protein contents (0-100 \%S),

434 and minimum absorption at $<280 \mathrm{~nm}$. It is known that proteins exhibit light absorbance around

$435280 \mathrm{~nm}$ mainly due to the presence of hydrophobic residues from tyrosine and tryptophan. A

436 slight shift of the typical maximum absorption for these amino acids residues was observed,

437 which may be attributed to the extremely high $\mathrm{pH}$ (10.5) which may cause the dissociation of

438 the carbonyl and amino groups. The increase in the absorbance of films with increasing SPI

439 proportions may be largely attributed to the exposure of a higher number of hydrophobic

440 residues which are present in the SPI. The transparency level of the films at $600 \mathrm{~nm}$ was not

441 significantly ( $>0.05$ ) modified due to the rate of S:G (Table 3).

442 The Hunter color parameters ( $\mathrm{L}^{*}, \mathrm{a}^{*} \mathrm{y} \mathrm{b}^{*}$ ) of the films are shown in Table 3. Soy films are

443 yellowish $(b+)$ while those made from gelatin are colorless. The color difference among

444 samples is a consequence of the formulation. As the proportion of soy in the formulation

445 increases, there is an increase in the yellowish color (b* is higher) and the films are more clear

446 ( $\mathrm{L}^{*}$ increases), these changes being significant for films formed with soy proportions higher

447 than $50 \%$. Since no changes in $a^{*}$ are observed, differences are mainly evidenced in the

448 intensity of the yellowish tone.

450 Conclusions

451 The polydisperse nature of gelatin molecules with the presence of unfolded fractions of high

452 molecular weight results in a film of considerable thickness, with extremely high deformability.

453 When the soy proteins (which preserves partially their globular structure) were introduced in Food Hydrocoll. 2009; 23(8) 2094-2101 
454 low concentration (25S:75G), gelatin aggregation as well as gelatin-SPI interactions were 455 induced, leading to a notable reinforcement of the composite film. As the proportion of soy 456 protein increased, the gelatin matrix approached saturation, in such a way that the formation of 457 an independent soy matrix would reduce the mechanical properties (both breaking force and 458 deformation) of the film.

459 Furthermore, soy proteins, which are well known to have surface hydrophobicities higher than 460 those of gelatin, would be also responsible for the better water vapor barrier properties of the 461 composite films. Although some physical properties have been improved (mainly breaking 462 force and WVP), composite films are still highly water sensitive, so that they are far from being 463 yet a real alternative to the plastic synthetic ones. However, they could be an excellent carrier of 464 active components to be used for food preservation or for designing functional foods.

465

466 Acknowledgements

467 This work has been performed within the framework of the project CYTED XI.20 and 468 sponsored by the Spanish Ministry of Education and Science under project AGL2005469 02380/ALI and by the National Agency of Scientific and Technological Support (SECyT,) of 470 Argentina under project PICT 35036/05.

471

472 References

473 A.O.A.C. 2000. Official Methods of Analysis. 17th Edition. In Association of Official 474 Analytical Chemistry. Maryland, USA.

475 Avena-Bustillos, R., Olsen C., Olson, D., Chiou, B., Yee, E., Bechtel, P. \& McHugh, T. (2006)

476 Water vapor permeability of mammalian and fish gelatin films. Journal of Food Science. 71 (4): $477 \quad 202-207$.

478 Barreto, P., Pires, A. \& Soldi, V. (2003) Thermal degradation of edible films based on milk 479 proteins and gelatin in inert atmosphere. Polymer Degradation and Stability. 79(1): 147-152.

480 Cao, N., Fu, Y. \& He, J. 2007. Preparation and physical properties of soy protein isolate and 481 gelatin composite films. Food Hydrocolloids. 21(7): 1153-1162. 
482 Carvalho, R., Sobral, P., Thomazine, M., Habitante, A., Giménez B., Gómez-Guillén, M., 483 Montero, P. (2008) Development of edible films based on differently processed Atlantic halibut 484 (Hippoglossus hippoglossus) skin gelatin. Food Hydrocolloids. 22(6): 1117-1123.

485 Chambi, H. \& Grosso, C. (2006) Edible films produced with gelatin and casein cross-linked 486 with transglutaminase. Food Research International. 39(4): 458-466.

487 Cho, S. \& Rhee, C. (2004) Mechanical properties and water vapor permeability of edible films 488 made from fractioned soy proteins with ultrafiltration. Lebensmittel-Wissenschaft und489 Technologie-Food Science and Technology. 37: 833-839.

490 Damodaran, S. \& Paraf, A. (1997) Food protein and their applications. New York: Plenum Press 491 Denavi, G., Tapia Blácido, D., Mauri, A., Sobral, P., Añón, M. \& Menegalli, F. (2008) Effects 492 of drying conditions on some physical properties of soy protein films. Journal of Food 493 Engineering. In press. doi:10.1016/j.jfoodeng.2008.07.001

494 Djagny, K., Wang, Z. \& Xu, S. (2001) Chemical modification of pigskin gelatin: Factors 495 affecting the esterification of gelatin with fatty acid. Journal of Food Science. 66(9): 1326-1330. 496 Gennadios, A. Protein based films and coatings. (2002). Florida: CRC Press.

497 Ghorpade, V., Li, H., Gennadios, A. \& Hanna, M. (1995). Chemically modified soy protein 498 films. Transactions of the ASAE. 38 (6): 1805-1808.

499 Gómez-Estaca, J., Montero, P., Fernández-Martín, F., Gómez-Guillén, M. (2008) Physico500 chemical and film forming properties of bovine-hide and tuna-skin gelatin: a comparative study.

501 Journal of Food Engineering. In press. doi:10.1016/j.jfoodeng.2008.07.022

502 Gómez-Guillén, M. \& Montero, P. (2001) Method for the production of gelatin of marine origin 503 and product thus obtained. International Patent PCT/·S01/00275.

504 Gómez-Guillén, M., Ihl, M., Bifani, V., Silva, A. \& Montero, P. (2007) Edible films made from 505 tuna-fish gelatin with antioxidant extracts of two different murta ecotypes leaves (Ugni molinae 506 Turcz). Food Hydrocolloids. 21(7): 1133-1143.

507 Gómez-Guillén, M. \& Montero, P. (2001). Method for the production of gelatin of marine 508 origin and product thus obtained. International Patent PCT/·S01/00275. 
509 Gómez-Guillén, M., Turnay, J., Fernández-Díaz, M., Ulmo, N., Lizarbe, M. \& Montero P.

510 (2002) Structural and physical properties of gelatin extracted from different marine species: a

511 comparative study. Food Hydrocolloids. 16 (1): 25-34.

512 Gontard, N., Guilbert, S., \& Cuq, J. L. (1992) Edible wheat gluten films: Influence of the main

513 process variables on film properties using response surface methodology. Journal of Food

514 Science, 57(1): 190-195.

515 Guan, J., Qiu, A., Liu, X., Hua, Y. \& Ma, Y. (2006) Microwave improvement of soy protein

516 isolate-saccharide graft reactions. Food Chemistry. 97(4): 577-585.

517 Güçbilmez, Ç., Yemenicioğlu, A. \& Arslanoğlu, A. (2007) Antimicrobial and antioxidant

518 activity of edible zein films incorporated with lysozyme, albumin proteins and disodium EDTA.

519 Food Research International. 40(1): 80-91.

520 Hägerdal, B. \& Martens, H. (1976). Influence of water content on the stability of

521 myglobin to heat treatment. Journal of Food Science. 41: 933-937.

522 Jongjareonrak, A., Benjakul, S., Visessanguan, W. \& Tanaka, M. (2006). Characterization of 523 edible films from skin gelatin of brownstripe red snapper and bigeye snapper. Food 524 Hydrocolloids. 20(4): 492-501.

525 Kim, K., Weller, C., Hanna, M. \& Gennadios, A. (2002). Heat curing of soy protein films at 526 selected temperatures and pressures. Lebensmittel-Wissenschaft und-Technologie. 35 140-145.

527 Kunte, L., Gennadios, A., Cuppett, S., Hanna, M. \& Weller, C. (1997) Cast films from soy 528 protein isolates and fractions. Cereal Chemistry. 74(2): 115-118.

529 Kurose, T., Urman, K., Otaigbe, J., Lochhead, R. \& Thames, S. (2007) Effect of uniaxial 530 drawing of soy protein isolate biopolymer film on structure and mechanical properties. Polymer 531 Engineering and Science. 47(4): 374-380.

532 Laemmli, U. (1970) Cleavage of structural proteins during the assembly of head of 533 bacteriophage T4. Nature. 227: 860-865. 
534 Ledward, D.A. 1986. Gelation of gelatin. In J.R. Mitchell, \& D.A. Ledward, Functional 535 Properties of Food Macromolecules (pp 171-201). London: Elsevier Applied Science 536 Publishers.

537 Longares, A., Monahan, F., O’Riordan, E. \& O’Sullivan, M. (2005) Physical properties of 538 edible films made from mixtures of sodium caseinate and WPI. International Dairy Journal. 539 15(12): 1255-1260.

540 Mauri, A. \& Añón, M. (2006) Effect of solution pH on solubility and some structural properties 541 of soybean protein isolate films. Journal of the Science of Food and Agriculture. 86(7): 10645421072.

543 Mauri, A. and Añón, M. C. (2008) Mechanical and physical properties of soy protein films with 544 pH modified microstructures. Food Science and Technology Internacional. 14 (2): 119-125.

545 McHugh H., Avena-Bustillos R. \& Krochta J. (1993) Hydrophilic edible films: Modified 546 procedure for water vapor permeability and explanation of thickness effects. Ibid. 58: 899-903.

547 Montero, P., Borderías, J., Turnay, J., \& Leyzarbe, M. A. (1990). Characterization of hake 548 (Merluccius merluccius L.) and trout (Salmo irideus Gibb) collagen. Journal of Agricultural and 549 Food Chemistry, 38(3), 604-609.

550 Muyonga, J., Cole, C. \& Duodu, K. (2004) Fourier transform infrared (FTIR) spectroscopic 551 study of acid soluble collagen and gelatin from skins and bones of young and adult Nile perch 552 (Lates niloticus). Food Chemistry. 86(3): 325-332.

553 Nagano, T., Motohiko, H., Mori, H., Kohyama, K. \& Nishinari, K. (1992) Dynamic viscoelastic 554 study on the gelation of conglycinin globulin from soybeans. Journal of Agricultural and Food 555 Chemistry. 40(6): 941-944.

556 Nanda, P., Rao, K., Kar, R. \& Nayak, P. (2007) Biodegradable polymers: Part VI. 557 Biodegradable plastics of soy protein isolate modified with thiourea. Journal of Thermal 558 Analysis and Calorimetry. 89(3): 935-940.

559 Nianbai Fang, N., Yu, S. \& Badger, T. (2004) Comprehensive phytochemical profile of soy 560 protein isolate. Journal of Agricultural and Food Chemistry. 52(12): 4012-4020 
561 Nielsen, N. (1985a). Structure of soy proteins. In A. Altshul \& H. Wilcke, New proteins foods

562 5: Seed strorage proteins (pp 27-60). Orlando: Academic Press.

563 Nielsen, N. (1985b). The structure and complexity of the 11S polypeptides in soybeans. Journal

564 of the American Oil Chemists’ Society. 62: 1680-1686.

565 Norland, R.E. (1990). Fish gelatin. In Advances in Fisheries Technology and Biotechnology for

566 Increased Profitability Eds. M.N. Voight \& J.K. Botta, Technomic Publishing Co., Lancaster, 567 pp.325-333.

568 Pérez-Mateos, M., Montero, P. \& Gómez-Guillén, M. (2009) Formulation and stability of 569 biodegradable films made from cod gelatin and sunflower oil blends. Food Hydrocolloids 570 23(1):53-61.

571 Petruccelli, S. \& Añón, C. (1995) Partial reduction of soy proteins isolate disulfide bonds.

572 Journal of Agricultural and Food Chemistry. 43, 2001-2006.

573 Piotrowska, B., Kolodziejska, I., Januszewska-Jozwiak, K. \& Wojtasz-Pajak, A. (2005) Effect

574 of transglutaminase on the solubility of chitosan-gelatin films. In H.Struszczyk, A. Domard,

575 M.G. Peter \& H. Pospieszny. Advances in chitin science (Vol VIII) (pp. 71-78). Poznan:

576 Institute of Plant Protection.

577 Rhim, J., Gennadios, A., Handa, A., Weller, C., \& Hanna, M. (2000). Solubility, tensile, and

578 color properties of modified soy protein isolate films. Journal of Agricultural and Food 579 Chemistry. 48(10): 4937-4941.

580 Sabato, S., Ouattara, B., Yu, H., D'Aprano, G., Le Tien, C., Mateescu, M. \& Lacroix, M. (2001)

581 Mechanical and barrier properties of cross-linked soy and whey protein based films. Journal of

582 Agricultural and Food Chemistry. 49(3): 1397-1403.

583 Sobral, P., Menegalli, F., Hubinger, M. \& Roques, M. (2001) Mechanical, water vapor barrier

584 and thermal properties of gelatin based edible films. Food Hydrocolloids. 15(4-6): 423-432.

585 Staswick, P., Hermedson, M. \& Nielsen, N. (1984) Identification of the cysteines which link

586 acidic and basic components of the glycinin. Journal of Biological Chemistry. 259 13431-

58713435. 
588 Stuchell, Y. \& Krochta, J. (1994) Enzymatic treatments and thermal effects on edible soy 589 protein films. Journal of Food Science. 59(6): 1332-1337.

590 Thanh, V. \& Shibasaki, K. (1977) $\beta$-conglycinin from soybean proteins. Isolation and 591 inmunological and physicochemical of the monomeric forms. Biochimica et Biophysica Acta, $592490(x) 370-376$.

593 Kim, K., Weller, C., Hanna, M. \& Gennadios, A. (2002). Heat curing of soy protein films at 594 selected temperatures and pressures. Lebensmittel-Wissenschaft und-Technologie. 35 140-145.

595 Yakimets, I., Wellner, N., Smith, A., Wilson, R., Farhat, I. \& Mitchell, J. (2005) Mechanical 596 properties with respect to water content of gelatin films in glassy state. Polymer. 46(26): 1257759712585.

598 Zhang, S., Wang, Y., Herring, J. \& Oh, J. (2007) Characterization of edible film fabricated with 599 channel catfish (Ictalurus punctatus) gelatin extract using selected pretreatment methods. 600 Journal of Food Science. 72(9): 498-503.

601 
603 Table 1. Naming system for films according to the proportion (w/w) of each protein.

604 Tabla 2. Thickness, water content and water solubility of films obtained with different 605 proportions of soy protein isolate (S) and cod gelatin (G).

606 Tabla 3. Color parameters $\left(\mathrm{L}^{*}, \mathrm{a}^{*}\right.$, and $\left.\mathrm{b}^{*}\right)$ of films formed with soy protein isolate and cod 607 gelatin.

608

609 Figure legends

610 Figure 1. DSC thermograms of films with different soy proteins:gelatin ratios.

611 Figura 2. SDS-PAGE gel show results for water soluble fraction of the films (Lanes 1 \& 7= 612 MW standards; 2 = 0S:100G; 3 = 25S:75G; 4 = 50S:50G; 5= 75S:25G; 6 =100G:0S)..

613 Figure 3. Water vapor permeability of films obtained with different soy protein:cod gelatin 614 proportions.

615 Figura 4. Mechanical properties as determined by the puncture test of films formed with SPI 616 and cod gelatin: a) breaking force (N); b) deformation (\%).

617 Figure 5. FTIR spectra of cod skin gelatin films (0S:100G), soy protein isolate films (100S:0G), 618 and their corresponding blends (25S:75G and 50S:50G).

619 Figure 6. Light barrier properties of films with different ratios of soy protein isolate and cod 620 gelatin 